\title{
A Análise de Discurso e "uma teoria da subjetividade (de natureza psicanalitica)"
}

Discourse Analysis and a theory of subjectivity (from psychoanalysis)

Lauro José Siqueira Baldini

Universidade Estadual de Campinas, Campinas, SP, Brasil

Resumo: Ao constituir o quadro epistemológico da Análise de Discurso, Michel Pêcheux o faz concebendo a Psicanálise como algo que atravessa os campos que ele, Pêcheux, coloca em contato e, mais ainda, ela os atravessa na medida em que os articula, através de sua teoria da subjetividade. No entanto, parece-me que não é trivial indagar: a que psicanálise se refere Pêcheux e o que se pode entender por uma teoria da subjetividade a partir da Psicanálise? Para ensaiar elementos de resposta a essa questão, iremos partir da leitura de um debate atual sobre essa questão, no interior do campo psicanalítico.

Palavras-chave: Discurso. Ideologia. Subjetividade. Inconsciente. Psicanálise.

Abstract: In creating the epistemological framework of Discourse Analysis, Michel Pêcheux conceives psychoanalysis as something that crosses the fields of knowledge that he articulates and, besides that, psychoanalysis articulates those fields through its theory of subjectivity. However, it seems to me that it is not trivial to ask: to what psychoanalysis refers Pêcheux and what can one understand by a theory of subjectivity from Psychoanalysis? Trying to put together elements to answer this question, we will start from reading a current debate on this issue within the psychoanalytic field.

Keywords: Discourse. Ideology. Subjectivity. Unconscious. Psychoanalysis. 
Lauro José

Siqueira

Baldini

O modo como a Psicanálise comparece na obra de Michel Pêcheux é motivo de discussão em perspectivas bastante variadas. Seja porque o campo da Psicanálise aparece de maneira que às vezes não é explícita nos textos de Pêcheux, seja porque a relação de Pêcheux com a Psicanálise nunca tenha sido a de uma adesão sem críticas, seja porque a relação entre o Materialismo Histórico e a Psicanálise tenha sido objeto de uma reflexão por vezes bastante complexa pelo autor ${ }^{1}$, o fato é que, a partir da obra de Pêcheux, embora a Psicanálise não possa deixar de ser tematizada, diferentes posições com referência ao quadro conceitual da Psicanálise podem ser inferidas.

De qualquer maneira, o que permanece como ponto central da questão entre Análise de Discurso e Psicanálise é que esta última fornece os elementos essenciais para que se possa pensar o conceito de sujeito e de subjetividade que interessam ao projeto de Pêcheux de uma análise histórica dos processos de determinação do sentido.

Vejamos, por exemplo, como ele articula o panorama conceitual da Análise de Discurso:

Ele reside, a nosso ver, na articulação de 3 regiões do conhecimento científico:

1) O materialismo histórico, como teoria das formações sociais e de suas transformações, compreendida aí a teoria das ideologias;

2) A linguística, como teoria dos mecanismos sintáticos e dos processos de enunciação ao mesmo tempo;

3) A teoria do discurso, como teoria da determinação histórica dos processos semânticos.

Convém explicitar ainda que estas três regiões são, de certo modo, atravessadas e articuladas por uma teoria da subjetividade (de natureza psicanalítica). (PÊCHEUX; FUCHS, 1993, p. 163-164, grifo nosso).

1 Também isso se dá pelo lado de Lacan. Em vários momentos, é possível ver em Lacan uma posição anti-historicista, bem como outras em que o diálogo com a história se faz presente. Trago três exemplos, entre outros, que poderiam ser arrolados. Em Estou falando com as paredes (1971-72), Lacan comenta sua teoria dos discursos (formulada, aliás, no mesmo momento em que tanto Pêcheux quanto Foucault investem numa análise discursiva): "Uns dois anos atrás, no caminho que tento traçar, consegui articular o que se passa com quatro discursos. Esses discursos não são os discursos históricos [...] Esses quatro discursos constituem de maneira tangível algo de real. Essa relação de fronteira entre o simbólico e o real nós vivemos nela, pode-se dizer" (LACAN, 2011, p. 60). Já no seminário A ética da psicanálise (1959-60), Lacan formula: "Reparem que não há avaliação correta possível da sublimação na arte se não pensamos nisto - que toda a produção da arte, especialmente das Belas-Artes, é historicamente datada" (LACAN, 2008, p. 132). Mais adiante, em Conferência em Genebra sobre o sintoma (1975), ele propõe, para guardar sua posição, o neologismo motérialisme, que, em francês, joga com mot (palavra) e matérialisme (materialismo). 
Note-se que a Psicanálise não comparece aí como um "quarto termo" do quadro geral proposto, mas como algo que atravessa os campos anteriormente mencionados. Mais ainda, ela os atravessa na medida em que articula, através de sua teoria da subjetividade, os campos referidos. No entanto, parece-me que não é trivial indagar: a que Psicanálise se refere Pêcheux e o que se pode entender por uma teoria da subjetividade a partir da Psicanálise?

o primeiro ponto é de mais fácil elucidação. Basta passar os olhos pela obra de Pêcheux para se dar conta de que suas referências, quando se trata da Psicanálise, são sempre a Jacques Lacan ou a autores que se vinculam ao campo lacaniano. Não é o caso, portanto, de se pensar numa referência a Winnicott, Klein, Bion ou a qualquer outro psicanalista de linha ou pensamento anglo-saxão que também, como

A Análise de Discurso e "uma teoria da subjetividade (de natureza psicanalítica)" Lacan, tenha se tornado um ponto de inflexão na história do movimento psicanalítico.

Porém, o segundo ponto merece um tratamento mais delicado. Se se trata de Lacan, qual a teoria da subjetividade que sustenta seu ensino e, além disso, como esta teoria atravessa e articula os campos da Linguística, do Materialismo Histórico e da Teoria do Discurso? Há em Lacan uma e apenas uma teoria do sujeito e da subjetividade que possa ser descrita?

Confesso que me falta a leitura necessária para dar conta dessa questão na profundidade que ela exige e que, além do mais, ultrapassa os limites de um artigo. Por outro lado, creio que a leitura de um debate atual sobre essa questão, no interior do campo psicanalítico, possa nos ajudar a compreendê-la.

Refiro-me, aqui, à questão de se pensar se se pode falar em uma nova subjetividade para os tempos que vivemos, ou até mesmo se o conceito de subjetividade admite uma historicização. Essa questão, pareceme, é central para compreendermos tanto a necessidade de Pêcheux em recorrer à Psicanálise quanto às críticas que este faz a essa prática. Para adentrar o tema, irei me focar em três artigos recentes, que julgo condensarem o ponto nodal de que se trata.

O primeiro texto que discutirei é de Erik Porge, que saiu publicado no Brasil em 2009, na revista Literal. Ali, o autor se coloca de maneira radical relativamente à questão do conceito de sujeito e de subjetividade que interessam à Psicanálise, de um ponto de vista lacaniano. Suas críticas se dirigem, sobretudo, a Melman (2008) e Lebrun (2008), ambos 
Lauro José

Siqueira

Baldini

psicanalistas, e, a partir de Lacan, propõe a existência de uma "Nova Economia Psíquica" ligada às transformações da contemporaneidade.

Porge começa seu texto situando a questão: trata-se de discutir, a partir dos trabalhos dos dois autores citados, se se poderia falar de uma nova subjetividade ou, nas palavras destes, de uma "Nova Economia Psíquica", a partir das modificações históricas do momento contemporâneo, que daria lugar a "neossujeitos", distintos daqueles que se teriam produzido em épocas anteriores. Trata-se, para Porge, de uma guinada em direção à Antropologia, e não "de contestar as mudanças na sociedade e seus efeitos psicológicos e sociais. Mas esse é o trabalho dos psicólogos e sociólogos. O ponto de vista do analista é outro" (PORGE, 2009, p. 147). Dessa maneira, o ponto central do esforço do texto de Porge não é indicar tanto a visão errônea dos trabalhos de Melman e Lebrun, mas de insistir que o ponto de vista de um psicanalista não pode, forçosamente, em razão de sua prática, ser este.

Se é verdade, como salientam Melman e Lebrun, que há um declínio da figura paterna e, em consequência, uma queda do simbólico como lugar terceiro que orientaria os laços sociais, para Porge, aquilo que Lacan nomeou como função do pai não pode ser reduzido a uma realidade fenomenológica² ${ }^{2}$ Nas palavras dele,

a ação do pai, seja ela identificada à metáfora ou ao pai nomeante, é independente de seu caráter na realidade ou de sua psicologia. Lacan não cessou de se pôr em guarda contra a confusão de natureza psicológica entre as carências paternas concretas na vida cotidiana e a falta do significante na metáfora (p. 147).

Assim, não se deveriam confundir as vicissitudes das modificações históricas da função paterna, tal como ela é exercida por esta ou aquela figura concreta, e sua função enquanto realidade estrutural demandada pela estrutura de linguagem do inconsciente. O que Porge vai criticar, portanto, é o empirismo que lhe parece estar subjacente nas propostas de Melman e Lebrun. Para o autor, falar em "nova economia

\footnotetext{
2 Não temos espaço para nos estendermos sobre essa questão aqui. Basta indicar que, para Lacan, a função paterna está ligada à função de nomeação do desejo da mãe, naquilo que se chama "metáfora paterna". Não se trata do romance familiar tal como ele pode ser entendido de um ponto de vista empírico, ponto que Lacan salientou mais de uma vez ao enfatizar que a falta do pai (concreto) não tem relação com a falta do pai (na metáfora).
} 
psíquica" é, por si mesmo, "um erro de nomeação, uma vez que conjuga, na prática e na doutrina, uma confusão entre a psicanálise, a sociologia e a psicologia" (p. 148). É essa confusão que está no cerne da crítica de Porge, e ele a situa no modo como se pensa o conceito de sujeito no trabalho dos autores citados. Nesse sentido, sua crítica deve interessar aos analistas de discurso, na medida em que o que está em questão é justamente aquilo que Pêcheux convocava como uma "teoria da subjetividade (de natureza psicanalítica)".

Tudo gira em torno de um texto de Lacan, o célebre "Discurso de Roma" ${ }^{3}$ em que aparece a expressão "subjetividade de sua época". Retomo o texto de Lacan:

Que antes renuncie a isso, portanto, aquele que não conseguir alcançar A Análise de Discurso e "uma teoria da subjetividade (de natureza psicanalítica)" em seu horizonte a subjetividade de sua época. Pois, como poderia fazer de seu ser o eixo de tantas vidas quem nada soubesse da dialética que o compromete com essas vidas num movimento simbólico. Que ele conheça bem a espiral a que o arrasta sua época na obra contínua de Babel, e que conheça sua função de intérprete na discórdia das línguas. (LACAN, 1998, p. 322).

A questão tem certa densidade linguística. Para Porge, o "isso" do início do parágrafo retoma "o engajamento do sujeito em sua prática" do parágrafo anterior. Para Melman e Lebrun, segundo Porge, o "isso" estaria retomando "a prática analítica", o que lhe parece incorreto. De qualquer maneira, essa é uma questão que remete a uma interpretação do texto de Lacan que, embora importante, não explicitarei aqui. Para o que me interessa, o nó é o modo como Porge (2009, p. 159) insiste em que

Lacan não fala de 'subjetividade para nossa época' [...] mas de um 'alcançar em seu horizonte a subjetividade de sua época'. Não se trata de fornecer um tributo a essa subjetividade, mas de alcançá-la, e mais, em seu horizonte.

Temos aí o eixo da argumentação: trata-se, para Porge, de um sujeito sem atributos, ou qualidades. Não haveria, portanto, "subjetividade geral comum a uma época" (PORGE, 2009, p. 151), para o autor, pois

3 Publicado nos Escritos, com o título "Função e campo da fala e da linguagem em psicanálise". 
Lauro José

Siqueira

Baldini

"sujeito e subjetividade são dois termos disjuntos que se excluem um ao outro no tempo em que aparecem" (p. 152). Além disso, ainda segundo o autor, a perspectiva de Melman e Lebrun introduz uma distinção bastante nociva, a de que "haveria então 'falsos' sujeitos sem subjetivação e 'verdadeiros' sujeitos com subjetivação” (p. 152). Retomando Lacan, Porge irá afirmar o seguinte: "o sujeito não tem subjetividade, ele não se subjetiva, ele se institui na sua destituição [...] porque ele é apenas representado por um significante para outro significante" (p. 152). A partir dessa interpretação do ensino lacaniano, qualquer relação entre a noção de sujeito e as novas formas da subjetividade ligadas ao fato histórico são um absurdo do ponto de vista analítico, isto é, do ponto de vista de uma prática psicanalítica, ou melhor, do dispositivo analítico. Como continua o autor,

Falar de 'novos sujeitos', como fazem os partidários da nova economia psíquica, é então um nonsense do ponto de vista da psicanálise. Seu sentido só pode ser psicológico, sociológico, jurídico... O analista é um generalista do sujeito, não um especialista de subjetividades (da criança, do adolescente, dos drogados, dos deprimidos... Das novas patologias, dos novos sujeitos). Generalizar de forma lógica a definição de sujeito (um significante o representa para outro significante), assim como as operações que ela permite (a alienação e a separação, por exemplo) permite escutar a fala de subjetividades a cada vez singulares. (PORGE, 2009, p. 152).

Para Porge, a consequência desse tipo de generalização é a surdez para a singularidade dos sujeitos que se dispõem à análise. Como ele afirma,

fazendo coincidir sujeitos e subjetividades com as determinações sociais (muito gerais e imprecisas) esquece-se a fala singular. Ali onde os sujeitos são identificados de fora, eles são fixados em uma identificação que faz identidade (PORGE, 2009, p. 155).

Se entendi bem, o ponto essencial é que, ao falar de novas subjetividades, os partidários da teoria de que há um novo funcionamento do psiquismo colocam em segundo plano a fala singular do sujeito para fazer aderir a esta uma descrição que vem "de fora", partindo de categorias que não são psicanalíticas, e sim sociológicas. 
O outro texto que trago para o debate, no entanto, propõe uma visão que julgo diferente da questão da relação entre sujeito e subjetividade, sem, contudo, estar alinhada à visão de Lebrun e Melman que Porge critica. Trata-se de "Da subjetividade contemporânea", de Sidi Askofaré, publicado em 2009. A pergunta de que parte Askofaré é a seguinte, em seus termos:

A Análise de

Discurso e

Por que 'subjetividade contemporânea' e não simplesmente 'sujeito contemporâneo'? Pode-se falar de um sujeito contemporâneo - o que evoca uma especificidade ligada ao tempo, à época e, portanto, à história - se o sujeito se define pelo seu assujeitamento à linguagem, e como o que um significante representa para um outro significante? Se sim, quais são as consequências a tirar daí, tanto no plano da doutrina quanto da "uma teoria da subjetividade (de natureza psicanalítica)" clínica? Se não, como conceber as relações entre sujeito e subjetividade e, sobretudo, como tirar partido disso na prática clínica e na análise do laço social e dos fenômenos coletivos? (ASKOFARÉ, 2009, p. 166).

Retomando a mesma citação de Lacan que Porge mobiliza anteriormente, Askofaré irá sustentar que a questão da relação entre sujeito e subjetividade é presente no próprio ensino de Lacan e que é preciso extrair daí as consequências possíveis.

Segundo o autor, a doxa psicanalítica sustenta algo que pode ser resumido nos seguintes termos:

o sujeito em psicanálise, o sujeito para a psicanálise é o sujeito do significante. Ele é o efeito, sem dúvida ativo, mas o efeito do significante; dito de outro modo, da linguagem. Ora, a linguagem, que se define como o sistema material dos significantes ou como o poder de simbolização que faz passar o real ao ser, é o que especifica o humano. o homem, portanto, é um 'falasser', um ser que fala, alguém que sustenta seu ser da fala. Deduz-se daí, então, quase matematicamente, que todo ser que é tomado na linguagem e que exerce a eminente função da fala seria um sujeito (ASKOFARÉ, 2009, p. 167).

Sem contestar tal doxa, que lhe parece poder ser extraída dos textos e do ensino de Lacan, o autor, no entanto, aponta uma dificuldade para se sustentar uma definição tão minimalista do sujeito, que faria com que fosse "difícil de conceber em que o sujeito do inconsciente que 
Lauro José

Siqueira

Baldini

124

interessa à psicanálise se distingue do sujeito dos gramáticos ou dos linguistas!" (ASKOFARÉ, 2009, p. 168). Assim, sua argumentação caminha no sentido de que não é essa a única definição de sujeito que se pode encontrar no ensino de Lacan. Para Askofaré (2009, p. 169), o sujeito, por exemplo, poderia ser pensado, a partir de Lacan, como "topológico: o sujeito como corte; dinâmico: o sujeito como defesa; tópico: o sujeito como suposto; econômico: o sujeito como desejo; ético: o sujeito como responsável".

Se o inconsciente é o discurso do Outro, como diz Lacan, para o autor,

o Outro, entendido nesse sentido, ou seja, o simbólico, se ele é invariável em sua estrutura - aquela da linguagem -, é também submetido às mudanças, às mutações, às rupturas, às subversões. Quem pode contestar as mudanças induzidas no Outro pelo advento do monoteísmo, a invenção da escrita, a emergência da ciência moderna e, mais recentemente, das biotecnologias e da informática?! (ASKOFARÉ, 2009, p. 169).

Para Askofaré, o que foi articulado por Lacan ao longo de seu percurso são, sim, as formas históricas de existência dos sujeitos humanos, e essas formas históricas têm sua relação com as modificações com o Outro, aqui entendido como o próprio simbólico, nas modificações que este assume segundo coordenadas que provêm do campo da História. Desse modo, produzem-se traços que podem ser deduzidos como os da subjetividade de uma época definida: "são as coordenadas de uma verdadeira subjetividade, quer dizer, de uma forma histórica e determinada de traços, de posições e de valores que os sujeitos de uma época têm em comum, em suas relações com o Outro, como discurso" (ASKOFARÉ, 2009, p. 170).

Segundo o autor, ainda que Lacan tenha tentado encontrar apoio na Linguística (num primeiro momento) para conseguir elucidar uma noção de sujeito que não fosse mera aplicação de um saber empírico sobre as condições culturais em que se movem os sujeitos falantes, isso não quer dizer que a noção de sujeito em Lacan seja esvaziada de qualquer referência a uma exterioridade (histórica): “qualquer que seja o apoio encontrado por Lacan na linguística ou na lógica para construir e formalizar seu conceito de sujeito, jamais essa referência obliterará que o sujeito tem coordenadas históricas e culturais muito precisas" (ASKOFARÉ, 2009, p. 171). 
A consequência clara de sua argumentação redunda em que, "para a psicanálise, portanto, o sujeito não é e não seria uma essência eterna, o conceito vazio e a-histórico do ser falante" (ASKOFARÉ, 2009, p. 174). Como se pode ver, esse texto difere, no modo como lê Lacan, da posição de Porge descrita anteriormente. Essa interpretação, inclusive, tem consequências clínicas muito precisas e, mais ainda, consequências que interessam diretamente aos analistas de discurso filiados à teoria de Michel Pêcheux. Deixemos a questão em suspenso.

O último texto que pretendo trazer aqui é o de Michel Plon: "Do sujeito em questão", de 2010. Neste trabalho, o autor também parte de uma crítica ao conceito de "Nova Economia Psíquica" proposto por Lebrun e Melman.

A primeira questão que Plon traz é a de que "a psicanálise não é

A Análise de Discurso e "uma teoria da subjetividade (de natureza psicanalítica)" uma disciplina, mas uma teoria articulada a uma prática radical" (PLON, 2010, p. 54). Nesse sentido, a psicanálise não pode ser pensada como mais uma teoria, um campo de saber sobre um mundo, uma relação de conhecimento entre sujeito e objeto, mas como uma teoria que se articula a uma prática: a prática da análise. A questão da clínica é central aqui.

Para Plon, se o leio bem, é evidente que há uma relação entre as modificações no campo social e aquilo de que se trata no inconsciente. Mas isso não se dá porque há uma nova forma de o psiquismo funcionar, e sim porque há uma mudança na maneira como a relação entre ciência e máquina produz efeitos políticos importantes. Nas palavras do autor,

o que constitui uma mudança, não nas estruturas psíquicas, mas no que lhes é dado apreender, é uma espécie de tendência à abolição de toda diferença entre o objeto de conhecimento, o campo do saber e a máquina. A máquina tende a ser não mais a coadjuvante do conhecimento, mas 0 próprio conhecimento: ela é, cada vez mais, A medicina, ela se torna $\mathrm{A}$ educação, ela é A política. (PLON, 2010, p. 60).

Evidentemente, tal consideração indica que, longe de desconsiderar a História, Plon a traz para pensar os efeitos que o desenvolvimento da ciência tem no funcionamento social mais geral. Porém, não se trata de falar de um novo psiquismo, e sim dos efeitos, no psiquismo, de uma despolitização e de uma medicalização na relação dos sujeitos com o sofrimento e com o saber. De fato, para Plon, falar em "Nova 
Economia Psíquica" é ver a psicanálise imersa no empirismo do qual Lacan tanto marcou distância com sua clínica estrutural. Vejamos:

Essas duas noções - notem que não falo de conceito -, sujeito e inconsciente, e a formulação lacaniana que delas resultou, a de sujeito do inconsciente, são de alguma forma reinvestidas e travestidas sub-repticiamente por meio de um modo de pensamento que pressupõe a existência anterior de entidades empíricas prontas a serem utilizadas por não

Lauro José

Siqueira

Baldini

126 importa que campo de conhecimento [...] sobre os quais se plasma, em seguida, o vocabulário psicanalítico. (PLON, 2010, p. 66).

Aproximando-se bastante de Porge, Plon irá marcar o que lhe parece ser uma constante do pensamento lacaniano, ou seja, a ideia de que o aforismo de que o significante representa o sujeito para outro significante dá a este, o sujeito, um caráter intervalar, não substancial, evanescente. Por essa via, toda atribuição de qualidade ao sujeito do inconsciente já seria, em si mesma, incompatível com a Psicanálise:

Lacan afirma em sua 'Proposição de outubro de 1967' que o sujeito não tem subjetividade, que ele não se subjetiva, que não existe de outra forma a não ser representado por um significante por outro significante, o que vai de encontro a toda teoria do signo, a toda teoria semiológica. 0 sujeito da psicanálise não é, pois, uma entidade concretizável, um sujeito geograficamente, economicamente determinável; ele não é o sujeito da sociologia, da história ou da política; ele não é de forma alguma assimilável ao indivíduo, ao ser filosófico; ele se desvanece no instante mesmo de sua enunciação. (PLON, 2010, p. 67-68, grifo do autor).

Os efeitos, para o autor, são claros: uma deriva historicista que exclui aquilo que interessa a uma clínica orientada pelo ensino lacaniano: a singularidade absoluta da fala de um sujeito. Dessa maneira,

Esse determinismo social do sujeito assim concebido, da subjetividade, abre caminho a uma deriva psicossociológica que foraclui a singularidade, a fala, em benefício de um logos estandardizado, que deseja completar a incompletude fundamental e inscrever em seu lugar uma tentativa de compreensão. (PLON, 2010, p. 68). 
No Brasil, apenas para ficar num exemplo, Safatle (2010) tem também se colocado a pensar a relação entre Psicanálise e História, sem, contudo, expressar adesão à proposição de que devam ser eleitas novas categorias conceituais, como as de "neossujeitos" ou a de uma "Nova Economia Psíquica". De fato, para o autor, esse tipo de paradigma de pensamento expressa, no fundo, uma nova roupagem para a crítica moral de comportamentos: "muitas vezes colocações dessa natureza são apenas versões modernizadas da crítica moral à sociedade contemporânea com seu pretendo hedonismo excessivo, sua recusa a aceitar a castração e a impossibilidade do gozo" (SAFATLE, 2010, p. 102).

Ora, para o que nos interessa aqui, a questão é que a proposta de Pêcheux representa um esboço em forma de enigma. Sabemos que, para ele, o ponto nodal da análise materialista de discurso que propunha era

A Análise de Discurso e "uma teoria da subjetividade (de natureza psicanalítica)" o de elucidar a relação entre a constituição do sujeito (pensada psicanaliticamente) e o assujeitamento ideológico, tal como este era pensado por Althusser. Em vários momentos, por exemplo, Pêcheux explicita essa relação traçando, de maneira muito sutil, momentos em que o inconsciente e a ideologia se atravessam. No anexo III, escrito em 1978 para uma nova versão de Semântica e discurso (1975), Pêcheux reconhece o efeito de "furo" do inconsciente em qualquer ritual de interpelação ideológica, ao mesmo tempo que atenta para o risco fácil de se fazer do inconsciente, agora, a origem da resistência das ideologias dominadas à ideologia dominante. Cito-o:

Retraçar a vitória do lapso e do ato 'falho' nas falhas da interpelação ideológica não se supõe que se faça agora do inconsciente a fonte da ideologia dominada, depois do fracasso de fazê-lo o impulso do superego da ideologia dominante: a ordem do inconsciente não coincide com a da ideologia, o recalque não se identifica com o assujeitamento e a repressão, mas isso não significa que a ideologia deva ser pensada sem referência ao registro inconsciente. (PÊCHEUX, 1988, p. 301).

Em outro texto, a mesma relação entre inconsciente e ideologia é desenhada na forma de um atravessamento do discurso pelas formações do inconsciente:

E através destas quebras de rituais, destas transgressões de fronteiras: o frágil questionamento de uma ordem, a partir da qual o lapso pode 
tornar-se discurso de rebelião, o ato falho, de motim e de insurreição: o momento imprevisível em que uma série heterogênea de efeitos individuais entra em ressonância e produz um acontecimento histórico, rompendo o círculo da repetição. (PÊCHEUX, 1990, p. 17).

O que é certo é que tanto a Análise de Discurso como a Psicanálise devem estar sempre prevenidas contra a vocação pastoral, para seguir a argumentação de Allouch $^{4}$ ao se referir a algumas visões psicanalíti-

Lauro José

Siqueira

Baldini

128 cas. A moral é uma questão que não deveria ocupar o espírito daqueles, analistas de discurso e psicanalistas, que estão ali para ouvir o que quer que venha a ser falado. Quanto ao que significa propriamente o recurso a uma "teoria da subjetividade (de natureza psicanalítica)", o debate me parece em aberto. Para que ele possa produzir seus efeitos, não basta que reconheçamos a existência do inconsciente e seu caráter de base para o assujeitamento ideológico. É preciso escolher um certo modo de ler Lacan, e de ler, em Lacan, aquilo que ele considerava sua investida fundamental: o campo do gozo. Portanto, o campo do desejo e da pulsão.

\section{Referências}

ALLOUCH, J. Avergonzados. 2005. Disponível em: <http://www. conversiones.com/nota0481.htm>. Acesso em: 10 abr. 2014.

ASKOFARÉ, S. Da subjetividade contemporânea. A Peste, São Paulo, v. 1, n. 1, p. 165-175, jan./jun. 2009.

LACAN, J. Função e campo da fala e da linguagem em psicanálise. In: Escritos. Rio de Janeiro: J. Zahar, 1998. p. 238-324.

(1959-60) Seminário, livro 7: a ética da psicanálise. Rio de Janeiro: J. Zahar, 2008.

(1971-72) Estou falando com as paredes. Rio de Janeiro: J. Zahar, 2011.

4 A citação: "Sostener su lugar? Eso quiere decir mantenerse radicalmente fuera de la medicina y fuera de la pastoral". 
LEBRUN, J. P. A perversão comum. Rio de Janeiro: Campo Matêmico, 2008.

MARIANI, B. Textos e conceitos fundadores em Michel Pêcheux: uma retomada em Althusser e Lacan. Alfa, v. 54, n.1, p.113-127, 2010.

MELMAN, C. O homem sem gravidade: gozar a qualquer preço. Rio de Janeiro: Cia. de Freud, 2008.

PÊCHEUX, M. [1975] Só há causa daquilo que falha ou o inverno político francês: início de uma retificação. In: Semântica e discurso: uma crítica à afirmação do óbvio. Campinas: Ed. da Unicamp, 1988.

A Análise de Discurso e "uma teoria da subjetividade (de natureza psicanalítica)"

Delimitações, inversões, deslocamentos. Cadernos de Estudos Linguísticos, Campinas: Unicamp/IEL, v. 19, p. 7-24, 1990.

; FUCHS, C. A propósito da análise automática do discurso: atualização e perspectivas [1975]. In: GADET, F.; HAK, T. (Org.). Por uma análise automática do discurso: uma introdução à obra de Michel Pêcheux. Campinas: Ed. da Unicamp, 1993. p. 163-252.

PLON, M. Análise do discurso (de Michel Pêcheux) vs análise do inconsciente. In: INDURSKY, F., LEANDRO FERREIRA, M. C. (Org.). Michel Pêcheux e a análise do discurso: uma relação de nunca acabar. São Carlos: Claraluz, 2005. p. 33-50.

Do sujeito em questão. In: MILÁN-RAMOS, J. G.; LEITE, N. V. A. (Org.). Terra-mar: litorais em psicanálise. Campinas: Mercado de Letras, 2010. p. 49-70.

PORGE, E. Um sujeito sem subjetividade. Literal, Campinas, n. 12, p. 145-158, 2009.

SAFATLE, V. Fetichismo. Rio de Janeiro: Civilização Brasileira, 2010. 